\title{
Analysis of the effect of size, amount and surface treatment on the tensile strain of a brittle adhesive reinforced with micro cork particles
}

\author{
A. Q. Barbosa ${ }^{1 *}\left(\mathbb{D}\right.$, L. F. M. da Silva², J. Abenojar ${ }^{3}$ and M. Figueiredo ${ }^{2}$
}

*Correspondence:

aqueiros@inegi.up.pt

${ }^{1}$ INEGI, Rua Dr. Roberto Frias, 400, 4200-465 Porto, Portugal

Full list of author information is available at the end of the article

\begin{abstract}
Nowadays, structural adhesives are increasingly being used for new applications, replacing conventional bonding methods. Epoxy resins are the most common structural adhesives used due to their suitable mechanical, thermal and chemical properties, despite their low ductility. In the past decades, several researchers have found it crucial to reverse these properties and find new ways to increase the ductility of these adhesives. The inclusion of particles (nano or micro) is an effective method to improve ductility of structural adhesives. In the present study, natural micro particles of cork are used with the objective of increasing the ductility of a brittle epoxy adhesive. The concept is for the cork particles to act like as a crack stopper leading to more energy absorption. The influence of the cork particle size, amount and the presence of a surface treatment were studied. The maximum strain of the adhesive was assessed through tensile tests. A Taguchi design experiments was used to understand the influence of each parameter under study (amount, size and presence of surface treatment) and their interaction. Through this research it was possible to settle that cork can improve ductility and cork amount, size and the use of plasma surface treatment have influence on the mechanical properties.
\end{abstract}

Keywords: Epoxy, Cork, Maximum strain, Micro-particles, Taguchi analysis

\section{Background}

Structural adhesives are an emerging joining method, increasingly selected in detriment to traditional joining methods. Even though the aeronautical industry was the main driving force of this technique, nowadays, adhesive joints can be used in other sectors such as aerospace, automotive, nautical, construction, electronics, or even in traditional applications such as footwear [1-3].

Epoxy resins are one of the structural adhesives with greater applicability, mainly due to their versatility and mechanical, thermal and chemical resistance. Epoxies present great strength and modulus of elasticity, low creep and good thermal resistance [1]. However, due to the high crosslinking, the polymeric structure presents low toughness and a low resistance to crack initiation and propagation $[4,5]$. There are some solutions 
available to improve ductility of brittle adhesives, like the inclusion of particles (inorganic or organic) [6,7]. Natural raw materials, such cork, can be used to improve ductility in brittle adhesives and currently different industries are encouraged to include these materials, with the aim to reduce the carbon footprint. Cork is an organic material with unique properties, obtained by a truly sustainable process, since it is renewable and biodegradable [8]. Cork is characterized by being lightweight, flexible, and substantially impermeable to liquids and gases, with excellent thermal, acoustic and vibration insulation, being also an innocuous and rootless material [9-11].

The use of a correct experimental methodology is a crucial task for the evaluation of a new adhesive. A proper analysis of the adhesive reinforced with cork should be achieved, in order to properly understand how the size, amount and surface treatment of cork particles can influence the adhesive properties. Failure strength tests are commonly used to determine the tensile stress-strain curve of bulk specimens and are a good approach to evaluate the adhesive mechanical properties, being frequently studied as part of the materials development process [12]. However, since there are some requirements that must be assured, the manufacture of bulk specimens is not an easy task. The presence of air bubbles must be reduced to obtain a complete filling of the mould and uncontrolled exothermic degradation of the adhesive during cure must be avoided. Additionally, a uniform distribution of the particles must be assured [12, 13].

The properties of the reinforced adhesive are not merely based on the properties of adhesive matrix or reinforcing particles, there are other parameters that contribute to the ductility improvement, which mainly influence the outcome of the composite material [4]. The parameters considered in this research are the volume fraction (amount), size of the particle and the interface particle/matrix; considering always a well-dispersed separate phase in the cured adhesive. The amount of particles dispersed in a structural adhesive matrix is a significant parameter in the subsequent mechanical properties of the adhesive [14-17]. The volume of particles is directly associated to the nature of the particles and their mechanical properties, so it is fundamental have full knowledge of the particles nature and properties.

Particle size is also a noteworthy parameter and should be evaluated with care, since it is a variable that can be controlled, and its importance is perceived at all stages of the adhesive production and subsequent application. The effect of particle size on the mechanical properties is not consensual, but some studies $[18,19]$ show that, for composites with micro scale particles, ductility generally increases with particle size.

The interface between the particles and the adhesive is also a key factor in the reinforcement process [18]. A good wetting between adhesive and the particles, favouring a strong bond, should be guaranteed [20]. Therefore, particles will act as crack stoppers and not as defects on the matrix. Chemistry of the particle surface is very important, as it defines both the rate of wetting and the strength of interaction with the adhesive [18]. So, to ensure appropriate interfacial interactions, their surface properties must be modified accordingly. Often it is suggested that some degree of modification or treatment should be applied to all surfaces prior to adhesive bonding, in order to make the surface more receptive to the adhesive $[21,22]$. In this study, plasma treatment was used to change the surface of the cork particles. Previous studies showed that the plasma treatment increases the wettability of the cork [21,23]. 
In this study, micro cork particles were used to increase the ductility of a brittle adhesive. Tensile tests were performed to assess the influence of the cork by particle size, amount and the presence of a surface treatment. To better comprehend the influence of each parameter and the interaction between them, the Taguchi method was used.

\section{Methods}

\section{Materials}

Araldite $2020^{\circledR}$, from Huntsman Advanced Materials (Pamplona, Spain), was the selected adhesive because it is very brittle, so the improvements on the ductility can easily be perceived. Araldite $2020^{\circledR}$ is a two component adhesive (100/30 by weight), resin (component A) and hardener (component $\mathrm{B}$ ). Component $\mathrm{A}$ is composed by diglycidyl ether of bisphenol A, (DGEBA) and diglycidyl ether of 1,4 butanediol (DGEBOH). On the other hand, component $\mathrm{B}$ is composed by isophorone diamine (IPDA). Since this adhesive is transparent and slightly viscous, the observation (with naked eye) of the cork particle distribution can also be easily performed. Each specimen was visually inspected before testing to ensure that the particle distribution was randomly uniform and there were no voids or other defects.

In this research, two distinct sizes of micro particles were used, within different range sizes: $38-53$ and $125-250 \mu \mathrm{m}$. The cork used was supplied by Amorim Cork Composites (Mozelos, Portugal), without any treatment.

\section{Surface plasma treatment}

Plasma treatment was used to modify the surface of the cork particles since it can considerably increase the surface wettability and decrease the contact angle [22, 24]. Low pressure plasma treatment was performed on a Plasma Cleaner chamber from Harrick Plasma (Ithaca, NY, USA), using air as the gas to produce the plasma on a surface of $70.85 \mathrm{~cm}^{2}$, at $0.29 \mathrm{kPa}$ of pressure. For the treatment in the chamber, $30 \mathrm{~W}$ of electric power for 1 min was used.

\section{Manufacture of bulk specimens}

A homogeneous mixture of cork micro particles in the adhesive must be guaranteed in order to avoid the introduction of air bubbles and ensure uniform distribution of particles. The cork was initially mixed with the resin using a centrifuge mixing machine, SpeedMixer DAC $150^{\mathrm{TM}}$ (Hauschild, Hamm, Germany), for $90 \mathrm{~s}$ at $1500 \mathrm{rpm}$. Before, the cork was mixed with the resin and after that, the hardener was added to the mixture. This procedure was the same for the different amounts and cork size. To ensure a better particle distribution after the mixing, the composite was heated to $50{ }^{\circ} \mathrm{C}$ for $15 \mathrm{~min}$, to accelerate the curing process. Thus, the particle distribution is improved since the upward movement of the particles is counteracted due to the difference in density between the particles and the epoxy resin. Afterwards, the composite was mixed again in the centrifuge mixing machine. This procedure was considered the most simple and effective way to prevent agglomeration of cork particles [8, 25].

After, the mixture was cast in a pre-heated steel mould. Release agent was applied to the mould to ensure an easy release of the bulk specimen. A silicone rubber frame was used to apply a hydrostatic pressure to the adhesive, which was hot pressed (2 MPa) for $15 \mathrm{~min}$ at $100{ }^{\circ} \mathrm{C}$ (according to the manufacturer's recommendation cure). Due to 
the combination of heat and pressure, the surface finish of the plate is excellent. This is crucial, since the mechanical properties are dependent of the presence of defects such as voids, microcracks and non-uniform particle distribution $[1,12]$. Specimens were machined from the plates manufactured with a mould [26]. The specimen production plan, varying cork presence, amount, size of cork particles and the presence of surface treatments, is shown in Fig. 1.

\section{Tensile tests}

Failure strength tests are commonly used to determine the tensile stress-strain curve of bulk specimens. This test was selected because the stress-strain curve can be used to determine the tensile strength, failure strain and Young's modulus. Figure 2 shows the dimensions of the machined specimens, with a thickness of $2 \mathrm{~mm}$. The tensile tests were carried out in an Instron 3367 universal testing machine (Norwood, USA), with a capacity of $30 \mathrm{kN}$. This test was made at room temperature and at a test speed of $1 \mathrm{~mm} /$ min. Three specimens were tested for each condition.

\section{Scanning electron microscopy analysis (SEM)}

Scanning electron microscope (SEM) analyses were performed in a JEOL JSM 6301F/ Oxford INCA Energy 350/Gatan Alto 2500 microscope (Tokyo, Japan) at CEMUP

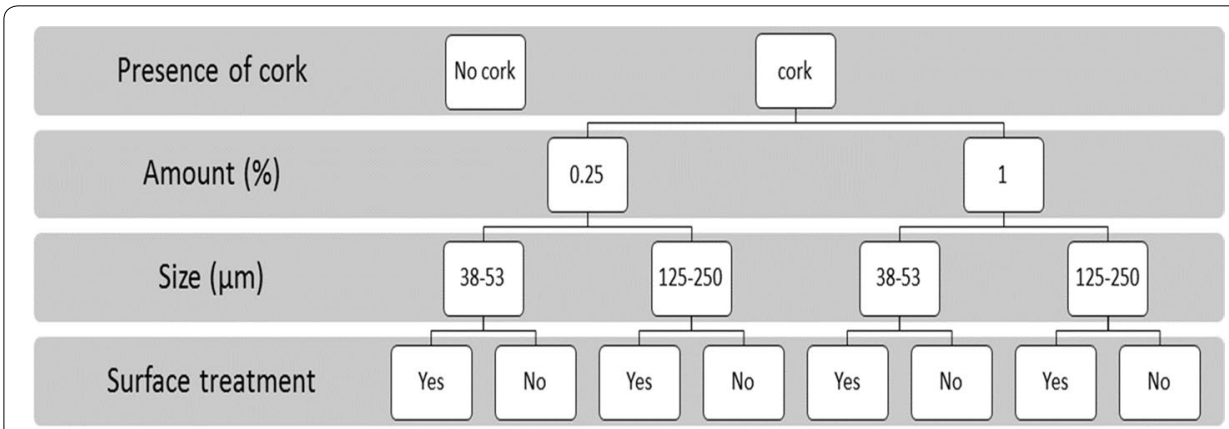

Fig. 1 Schematic diagram of cork specimens with different parameters used for Taguchi analysis: amounts (\% in volume), size, surface treatment

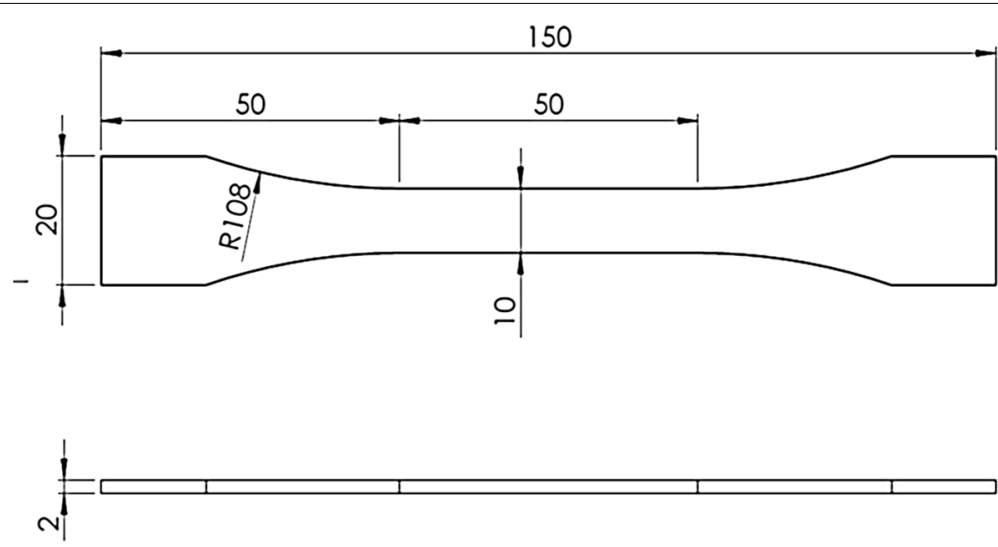

Fig. 2 Dog-bone tensile test specimens according to BS 2782 standard (dimensions in mm) 
(University of Porto, Portugal). This equipment was used to analyse the cork particles, particle distribution and surface fractures. Samples were coated with an $\mathrm{Au} / \mathrm{Pd}$ thin film, by sputtering, using the SPI Module Sputter Coater equipment, for $120 \mathrm{~s}$ and with a $15 \mathrm{~mA}$ current.

\section{Taguchi design experiments}

The Taguchi method was the methodology used to design the experiments [27-29]. The Taguchi orthogonal array used contains three variables, corresponding to the size, amount and surface plasma treatment, therefore, a $\mathrm{L}_{8}\left(2^{7}\right)$ table was applied (Table 1 ). $\mathrm{L}_{8}\left(2^{7}\right)$ allows to quantify the main effects and interactions between the variables considered. The influence of each variable and its interactions was assessed by the average response and the analysis of variance, ANOVA (SuperANOVA version v1.11, Abacus Concepts, Inc. 1991).

\section{Results and discussion}

\section{Cork particles characterization}

Particles with and without plasma surface treatment were characterized using SEM, for size, shape and wall thickness. In particles with and without surface plasma treatment, particles with 125-250 $\mu \mathrm{m}$ size presented a honeycomb structure composed by several cells, some open (edges of particles), but also closed cells (particle core) (see Fig. 3). Particles with 38-53 $\mu \mathrm{m}$ size have damaged cell walls, and in some cases these particles present only cell walls fragments (see Fig. 4). Some modifications are perceived compared to the particles that were not treated, when the surfaces that have been treated with plasma were analysed. Regarding to the thickness of the cell walls, it was found that treated particles present smaller thickness comparing to particles that did not have surface treatment. Measurements were performed at various cell walls and a decrease of cell wall thickness of $3.6 \%$ was detected in particles sized between 38 and $53 \mu \mathrm{m}$ and a decrease of $3.3 \%$ in particles sized between 125 and $250 \mu \mathrm{m}$. This fact reveals that the plasma treatment is responsible for the erosion of the cell walls. This might enable the introduction of resin inside the cork cells and thus compromising the mechanical properties of the composite.

Table 1 Taguchi $L_{8}\left(2^{7}\right)$ orthogonal array, with all variables in study (size, amount and plasma surface treatment)

\begin{tabular}{llll}
\hline Test & \multicolumn{2}{l}{ Variable } & Amount (\%) \\
\cline { 2 - 4 } & Size $(\boldsymbol{\mu m})$ & 0.25 & Plasma surface treatment \\
\hline 1 & $53-38$ & 0.25 & With \\
2 & $53-38$ & 1 & Without \\
3 & $53-38$ & 1 & With \\
4 & $53-38$ & 0.25 & Without \\
5 & $125-250$ & 0.25 & With \\
6 & $125-250$ & 1 & Without \\
7 & $125-250$ & 1 & With \\
8 & $125-250$ & 1 & Without \\
\hline
\end{tabular}




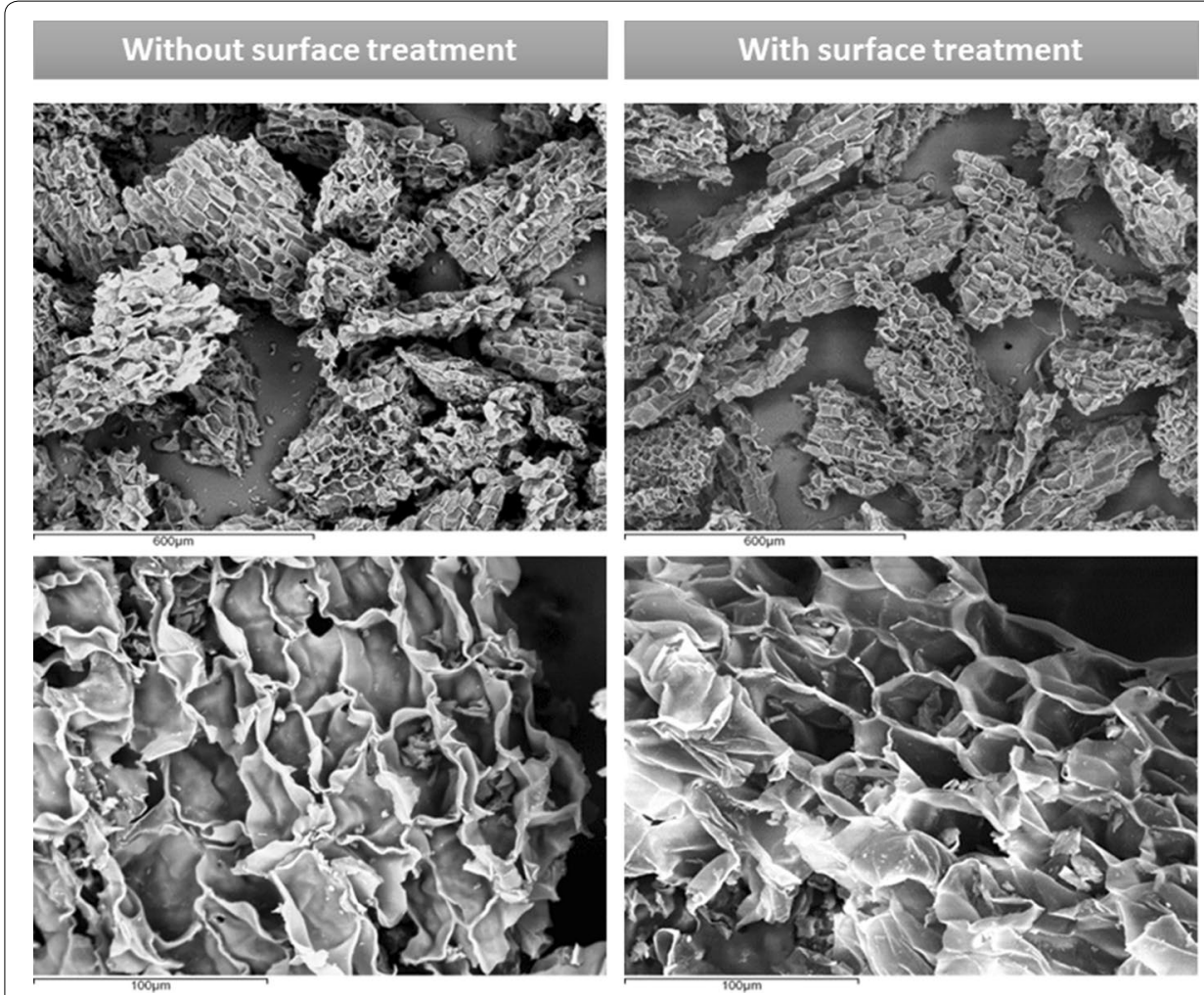

Fig. 3 Cork particles characterization with and without surface treatment, 125-250 $\mu \mathrm{m}$

\section{Tensile tests}

In previous studies it was observed that the presence of cork particles (different, size amount and surface treatment) changes the mechanical properties of the adhesive [22, $23,30,31]$. However, so far the influence of each variable and its interaction, regarding to failure strength test has not been assessed. Figures 5 and 6 show typical tensile stressstrain curves of neat resin and of the epoxy resin with different amounts and particles size, for cork with and without surface plasma treatment, respectively. It can be seen that size, amount and plasma treatment influence the mechanical properties of cork/ resin composites. For specimens without surface treatments, small particles and higher amounts of cork particles present higher strain value whereas a small amount of bigger particles present worse results than the neat resin. Specimens without surface treatment present higher strain values than specimens with surface treatment.

Cork particles may act as a reinforcing material and several mechanical properties are also inherently changed. Among them are the impact toughness, Young's modulus, maximum strain and stress and glass transition temperature. It is also important to remember that the properties of a reinforced adhesive are not solely ruled by the properties of the adhesive matrix or the reinforcing material. In fact, there are several other parameters involved in the determination of the properties of the material, which largely influence the performance of the composite material, such as particle size, and amount and also interface between particle and matrix. Analysing Figs. 7, 8, 9, it can be clearly observed that the Young's modulus, maximum tensile stress and strain vary 
with the size, amount and surface treatment of cork particles. Specimens with surface plasma treatment present lower values of maximum tensile stress than specimens without surface treatments, and in some cases lower than the neat resin. Regarding to Young's Modulus, specimens without surface treatment, present higher value than specimens with surface treatment (except specimen with 1\% for 125-250 particle size).
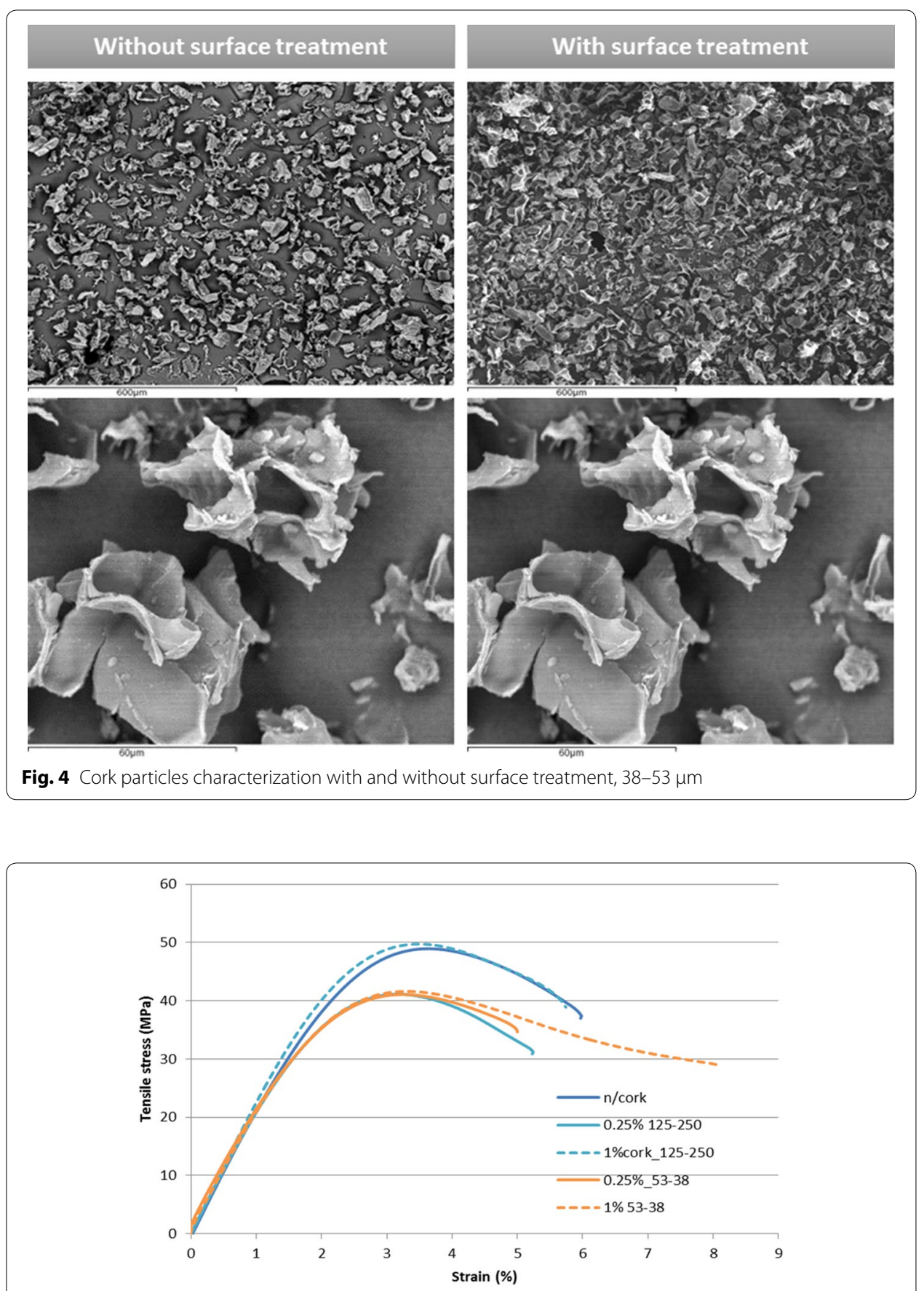

Fig. 5 Tensile stress-strain curves of specimens with different cork amounts (0, 0.25 and 1\%), different particle size, with surface treatment 


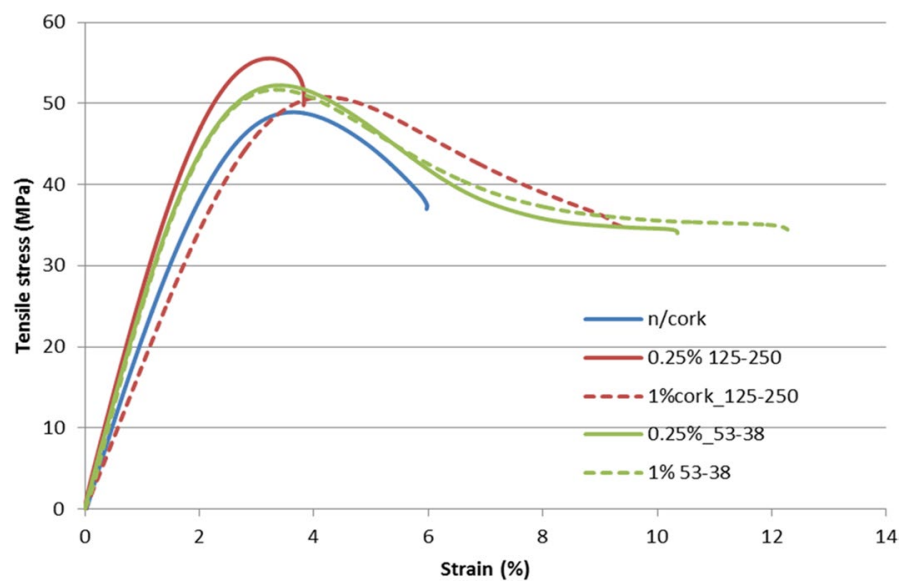

Fig. 6 Tensile stress-strain curves of specimens with different cork amounts (0, 0.25 and 1\%), different particle size, without surface treatment

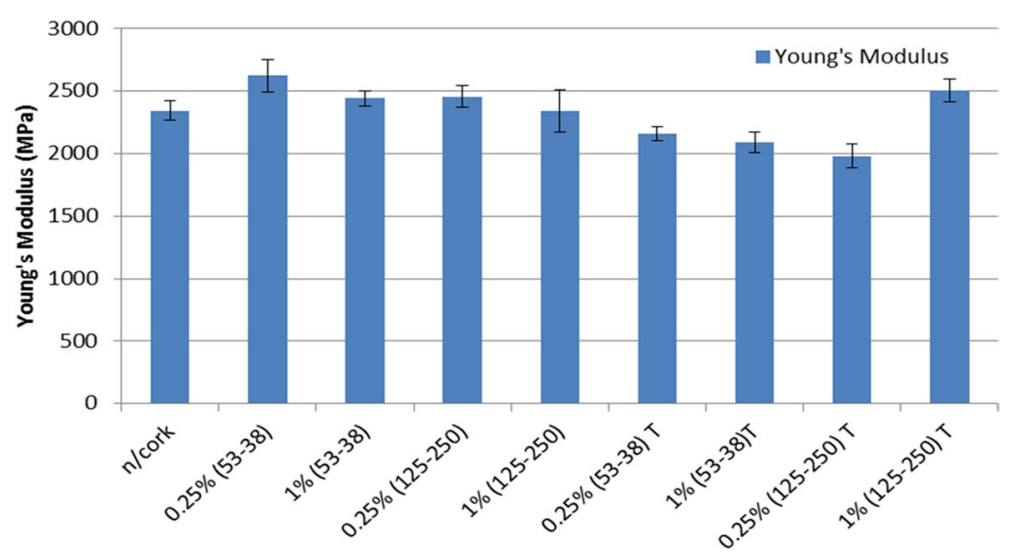

Fig. 7 Young's modulus of specimens with different amount, size and surface treatment of cork particles. T means with surface plasma treatment

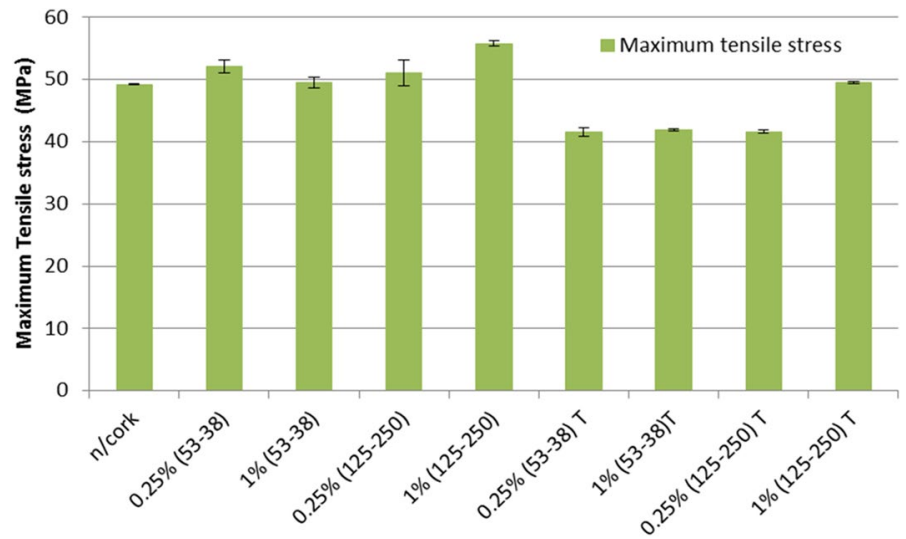

Fig. 8 Maximum tensile stress of specimens with different amount, size and surface treatment of cork particles. T means with surface plasma treatment 


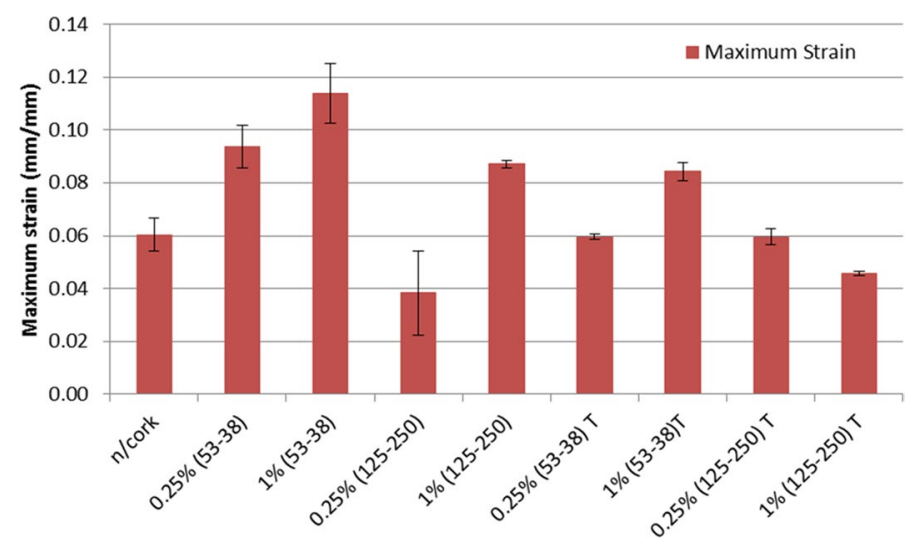

Fig. 9 Maximum strain of specimens with different amount, size and surface treatment of cork particles. $T$ means with surface plasma treatment

Nevertheless, it is not so easy to do the same analysis when the results of maximum strain. Therefore, to perform the analysis of these results the Taguchi method was used.

\section{Fracture surface analysis}

In order to have a complete understanding of the effect of the particle amount, size and surface treatment on the tensile strain, fractographic studies of the tensile test specimens fracture surface were performed, using SEM. In both cases (with or without surface treatment), it is evident that cork particles are randomly distributed and well spread in the epoxy resin matrix (see Figs. 10, 11 respectively). In a first approach, it is also possible to say that all specimens present a fracture surface that indicate a brittle behaviour, showing a quite smooth fracture surface in the slow growth zone. The fracture surfaces are in agreement with the results obtained in tensile tests as the specimens that present

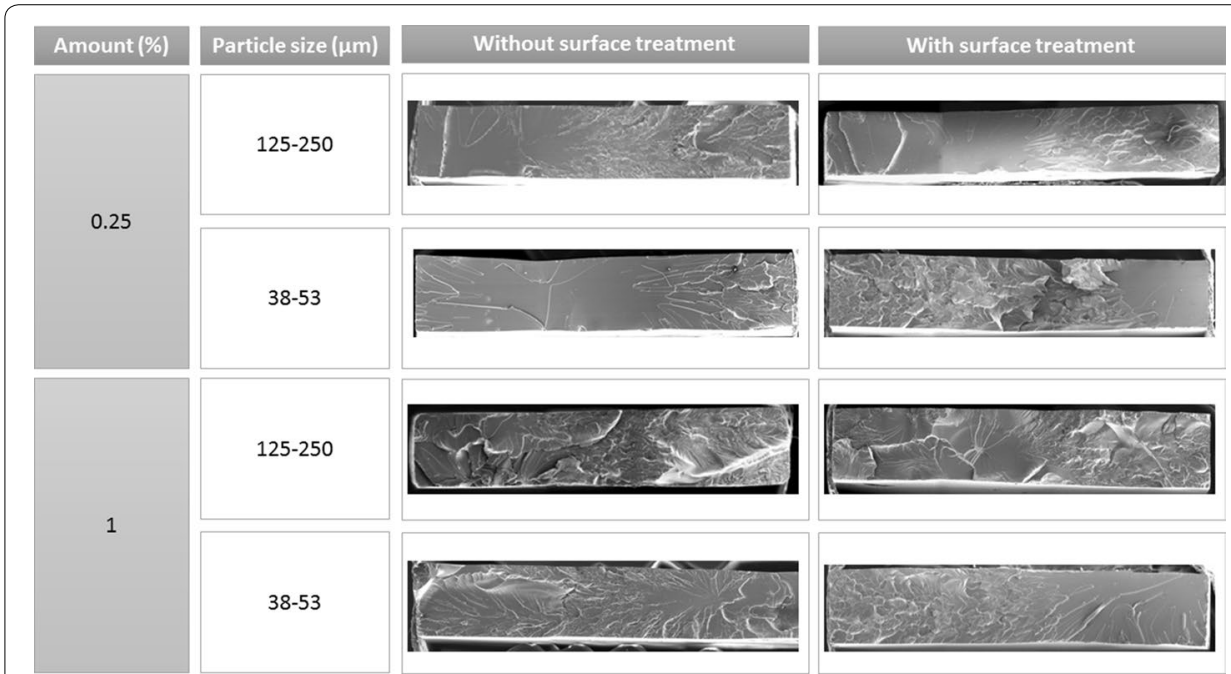

Fig. 10 Fracture surfaces with different cork amounts and size for specimens without and with plasma surface treatment 


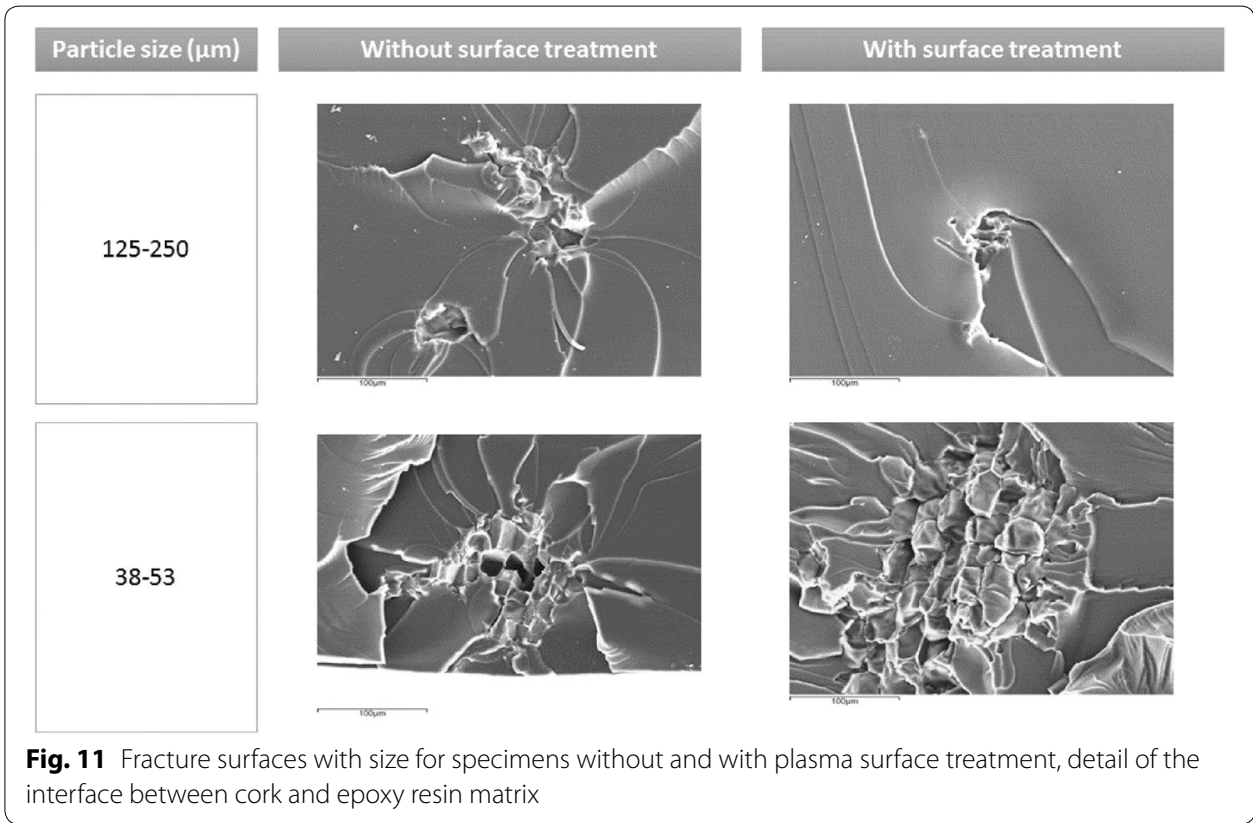

less the brittle behavior are the specimens without surface treatment and $1 \%$ of cork, regardless of the particle size. Therefore, it is possible to note that the major influence on the fracture surface derives from the particle amount. Specimens with plasma surface treatment have a more brittle fracture surface than specimens without plasma surface treatment.

\section{Analysis of maximum strain results-analysis of variance and average response}

As mention in a previous section, it is difficult to define a pattern behaviour between the size and amount of incorporated cork and plasma surface treatment. Therefore, a Taguchi orthogonal array (Table 1) was used to determine which variable present the greatest influence and interactions between the given possibilities. In Table 2, P value is the value for $\alpha<0.05$ of significance and $\mathrm{P}$ is the contribution. Table 2 presents the ANOVA of the data with the parameters and interactions significant for $95 \%$ confidence. This table shows that the size has the major influence on the maximum strain results (37\% of contribution), followed by the amount (18\%). The surface treatment is the parameter with less influence (17\%). The strongest interaction is size vs surface treatment, with $6 \%$ of contribution.

Figure 12 presents the main effect of particle size. Specimens with smaller $(38-53 \mu \mathrm{m})$ particles present a higher value of maximum strain, reaching an increase of $55 \%$ in

Table 2 ANOVA analysis with all parameter and interactions, considering maximum strain

\begin{tabular}{lcllllr}
\hline Source & df & Sum of squares & Mean square & F value & P value & P (\%) \\
\hline Amount $(\%)$ & 1 & 0.003 & 0.003 & 20.297 & 0.0003 & 18 \\
Size $(\mu \mathrm{m})$ & 1 & 0.006 & 0.007 & 40.346 & 0.0001 & 37 \\
Surface treatment & 1 & 0.003 & 0.003 & 18.888 & 0.0004 & 17 \\
Size * surface treatment & 1 & 0.001 & 0.001 & 7.761 & 0.0127 & 6 \\
Residual & 17 & 0.003 & 0.0001 & & & 22 \\
\hline
\end{tabular}




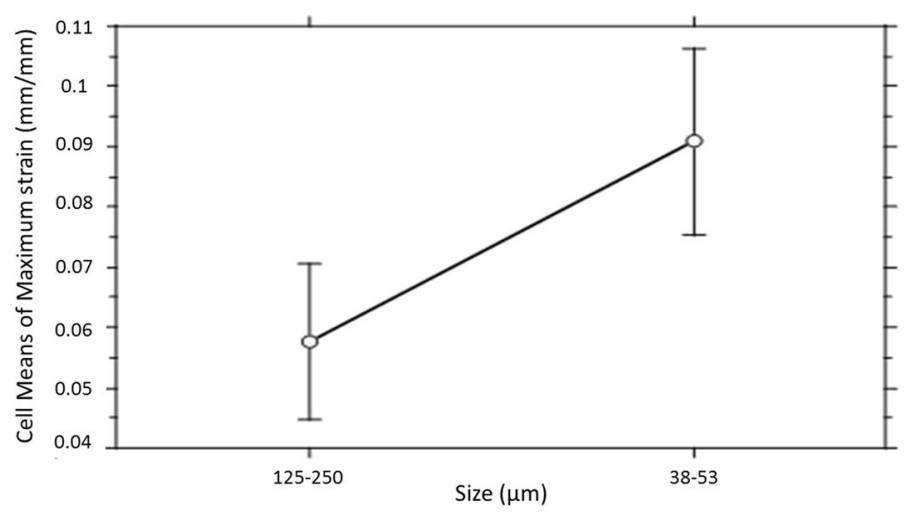

Fig. 12 Main effect of cork particles size on maximum strain, average results with 95\% confidence error bars

maximum strain comparing to bigger particles. Since this research intends to reach the best combination to improve the ductility of the adhesive, it can be concluded that the small particles are the best option in case of tensile loading. Several authors have studied the effect of particle size on the mechanical performance of thermosetting polymers [20,32,33]. Some studies [19, 34] indicate that, for composites with micro scale particles, fracture toughness generally increases with particle size, but this analysis is not consensual.

Figure 13 shows the effect of particle amount on maximum strain. Specimens with $1 \%$ of cork present the highest value of maximum strain. On the other hand, specimens with $0.25 \%$ of cork present lower values of maximum strain and higher dispersion. As found in previous research $[8,22,25]$, cork particles do not present a standardized structure as it can vary depending on biological and/or mechanical factors, which are very challenging to control. Therefore, there is an inherent dispersion of results that stems from the conditions of the cork particles. With the decrease of the amount of cork particles, the results dispersion increases, as seen in Fig. 13. As mentioned in Table 2, the cork particles amount represents an influence of $18 \%$ on maximum strain results. This result can also be detected by the line slope, which joins the two graphed values. The lower the influence of a parameter, the lower the slope of the line.

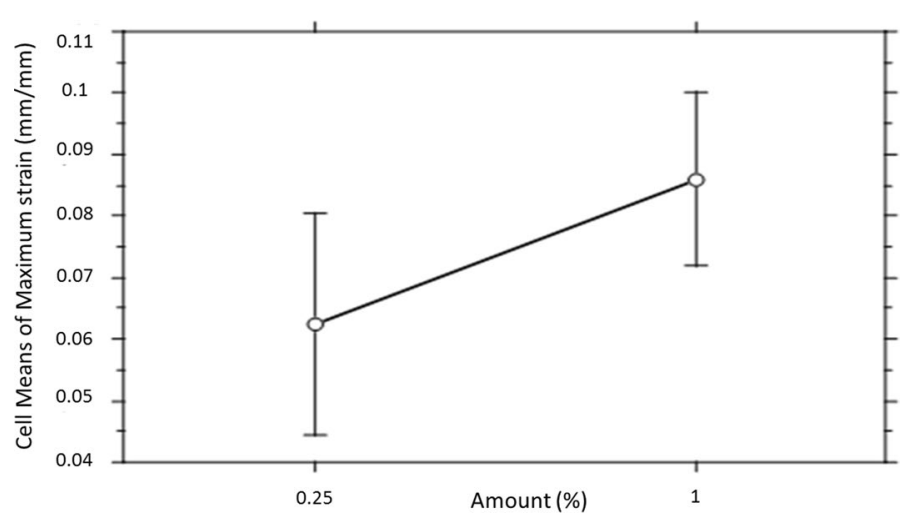

Fig. 13 Main effect of cork particles amount on maximum strain, average results with 95\% confidence error bars 
Figure 14 presents the effect of plasma surface treatment on maximum strain. According to the Taguchi analysis, surface treatment presents the lowest influence on the maximum strain results (17\%). Specimens with plasma surface treatment present a lower value of maximum strain, on the other hand, specimens without surface treatment present higher maximum strain values but also a higher dispersion of the results. As this research aim to reach the best combination to improve the ductility of the adhesive, it can be established that the surface treatment will not be the best solution. The cork particles mechanical properties and structural integrity are compromised, despite the improvement on wettability between the epoxy resin and cork particles.

It is important to study the influence of each parameter, but also the interaction between parameters to better optimize the process in order to select the best combination possible. For 95\% confidence, the only interaction study was surface treatment vs particle size (see Fig. 15). Specimens with plasma surface treatment present low maximum strain values, unrelatedly to the particle size. Inversely, the behaviour of specimens without plasma surface treatment differs with particle size, as specimens with

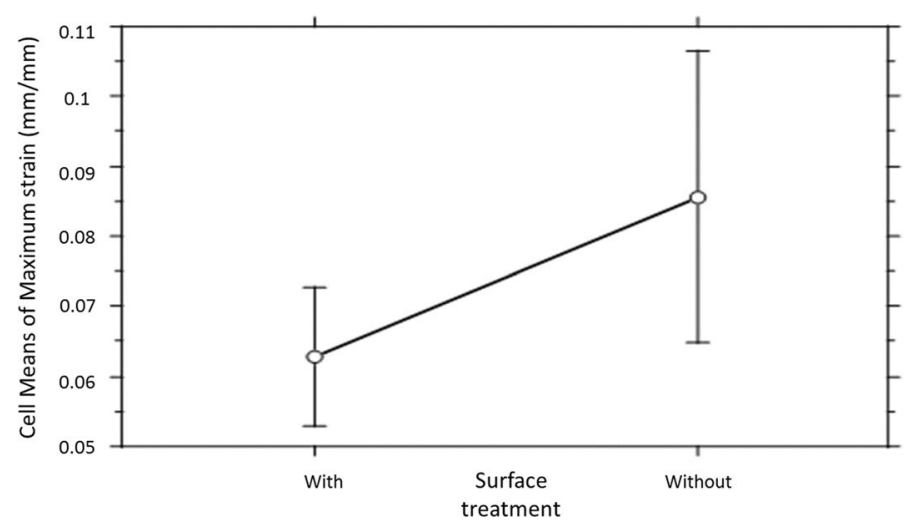

Fig. 14 Main effect of cork particles plasma surface treatment on maximum strain, average results with 95\% confidence error bars

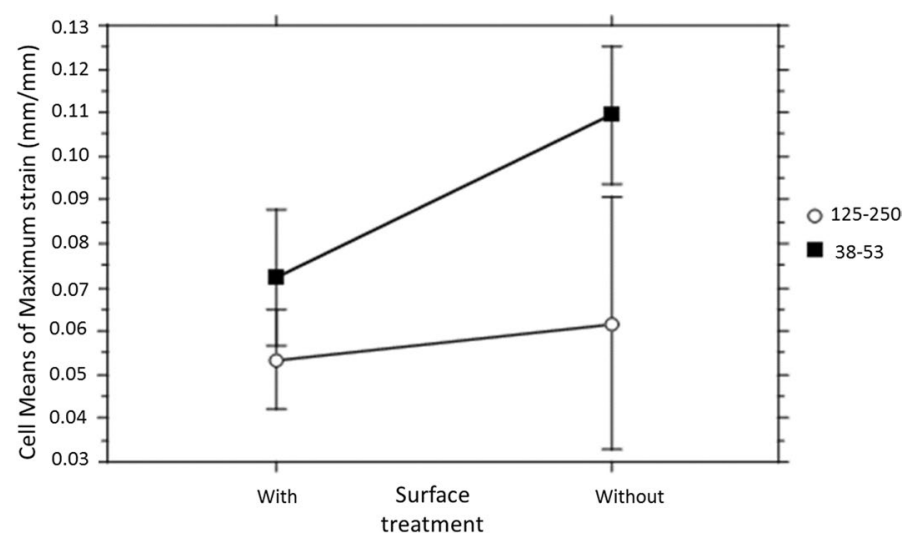

Fig. 15 Interaction on effect of cork particles size vs surface treatment on maximum strain, average results with $95 \%$ confidence error bars 
small particles present higher values of maximum strain. Nonetheless, it must be taken into account that there is noteworthy dispersion in these results and, therefore, this can only be considered as a trend. It is easily observed that for specimens with bigger particles (125-250 $\mu \mathrm{m})$, surface treatment does not present a great influence, compared to smaller particles $(38-53 \mu \mathrm{m})$. The smaller particles are more susceptible to the effect of surface plasma treatment, since they are composed of only a few cells (between 1 and 3). Therefore, in case of erosion and the cellular structure be compromised, the particle mechanical properties easily decrease with the surface treatment. On the other hand, on larger particles this effect is not as pronounced as these particles are composed of several cells (always more than 5). Once again, it is observed from these results that the practice of surface treatment is not an asset.

\section{Taguchi analysis of maximum strain results-multiple regression}

A multiple regression can be applied to obtain a maximum strain prediction, built using the relationship between the three independent variables. The regression coefficients of maximum strain values versus the three independent variables are given in Table 3.

With this information, it is possible to formulate an equation to predict the maximum strain of the adhesive by altering the size, amount and the application of surface treatment of micro cork particles (see Eq. 1). In this regression, surface treatment is a dummy variable, taking the value " 0 " for specimens without plasma surface treatment and "1" for specimens with plasma surface treatment. This equation is valid for particle size between 38 and $250 \mu \mathrm{m}$ and amount between 0.25 and $1 \%$, with a determination coefficient $\left(R^{2}\right)$ of 0.744 .

$$
\begin{aligned}
\text { Maximum strain }= & 0.093+0.031 \times \text { Amount }-2.342 \times 10^{-4} \\
& \times \text { size }-0.023 \times \text { surface treatment }
\end{aligned}
$$

The experimental results were used to validate the formulated equation. In addition to the previous tested conditions, two additional conditions that were used for the formulation of the equation were tested: neat resin, specimens with $0.5 \%$ cork, $125-$ $250 \mu \mathrm{m}$ size without surface treatment and specimens with $2 \%$ cork, $125-250 \mu \mathrm{m}$ size without surface treatment. The values presented by the specimen neat resin and $2 \%$ cork, 125-250 $\mu \mathrm{m}$ size without surface treatment are not covered by Eq. 1, being outside of its range of values. However, this analysis was made to perceive if the values of the equation can be extrapolated. Figure 16 presents the experimental values and also the analytical values obtained by Eq. 1 . The correlation between the experimental values and

Table 3 Regression coefficients of maximum strain versus three independent variables, with $R^{2}$ of 0.744

\begin{tabular}{llllrr}
\hline & Coefficient & Std. error & Std. coefficient & t value & P value \\
\hline Intercept & 0.093 & 0.008 & 0.093 & 11.128 & $<0.0001$ \\
Amount $(\%)$ & 0.031 & 0.008 & 0.436 & 3.848 & 0.0010 \\
Size $(\mu \mathrm{m})$ & $-2.342 \mathrm{E}-4$ & $-4.316 \mathrm{E}-4$ & -0.614 & -5.425 & $<0.0001$ \\
Surface treatment & -0.023 & 0.006 & -0.420 & -3.712 & 0.0014 \\
\hline
\end{tabular}




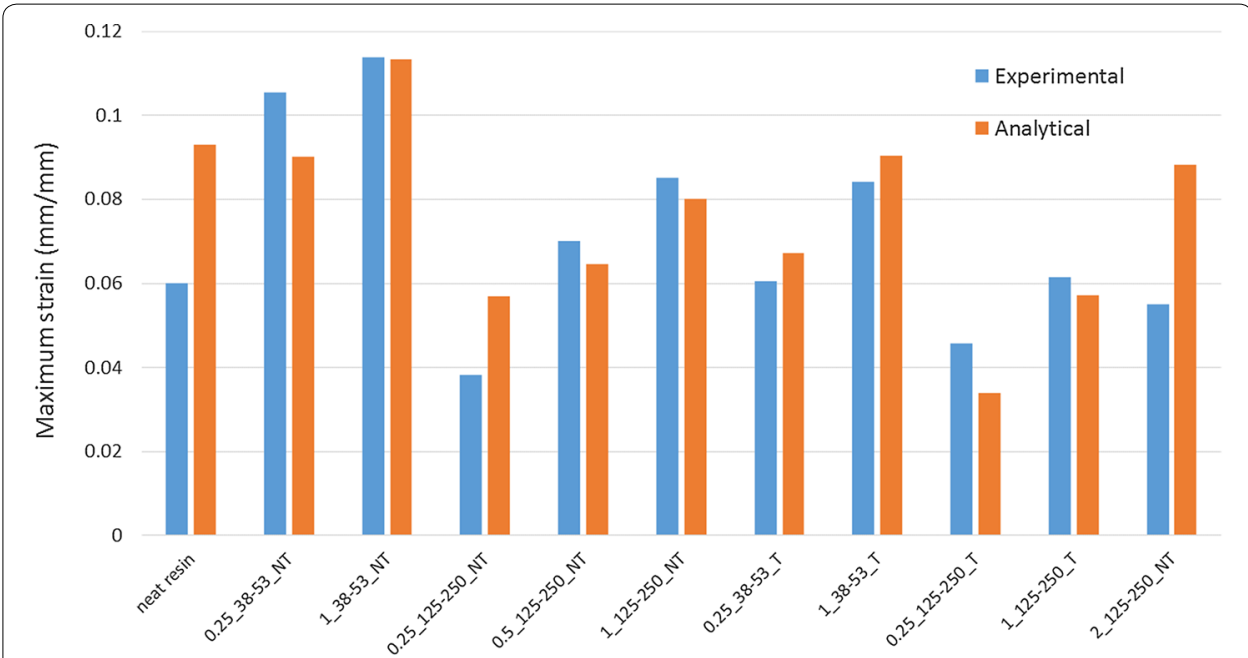

Fig. 16 Comparison between the experimental values and the analytical values of maximum strain

the analytical values is reasonable within the range of the equation but does not compare very well when outside the range. However, the equation shows to be a suitable tool to predict the mechanical behaviour of the reinforced adhesive, as it provides a reasonable estimate of the experimental value. As observed for the results of the samples of $2 \%$ cork and $125-250 \mu \mathrm{m}$ particle size without surface treatment, it is not advisable to extrapolate the results to values outside the range of variables considered, since the prediction may not be precise.

\section{Conclusions}

The effect of particle size, amount and surface plasma treatment of micro cork particles on the maximum strain of a brittle epoxy resin was assessed through tensile tests, and analysed using the Taguchi method. These tests were performed on neat epoxy resin and epoxy resin reinforced with micro cork particles. The following conclusions can be drawn:

- Plasma treatment is responsible for an erosion of cell walls, leading to a decrease in cell wall thickness;

- The particle amount, size and plasma surface treatment have an effect on the adhesive maximum strain. Specimens reinforced with treated cork particles present maximum strain values lower than the majority of specimens reinforced with particles without surface plasma treatment. In contrast, the specimens with cork without surface treatment show higher values of maximum strain compared to those of the neat resin (with an exception for $0.25 \%$ cork $125-250 \mu \mathrm{m}$ size);

- Maximum strain values are in agreement with the fracture surfaces: higher values of maximum strain are consistent with less brittle fracture surfaces;

- The Taguchi method is a useful tool to scrutinise parameters and perceive variable influences and their interactions. Size shows the main influence on the maximum strain results, followed by the amount; surface treatment being the parameter with less influence in this analysis. Regarding the interaction between the parameters, the only interaction considered was size vs surface treatment; 
- The formulated equation is shown to be an expedited tool for predicting maximum strain results.

- As a final remark, it can be said that the use of micro cork particles as a reinforcing material can be an excellent industrial application of a natural product. In addition of being seemingly technically possible, this technique would also allow the use of a product (cork powder) that is currently not exploited by the cork industry and which has an important impact in the Portuguese economy. Cork powder is normally burnt, leading to unnecessary energy consumption and frequent accidents. The successful use of this material for reinforcing epoxies would open a completely new market for the cork industry, with many potential benefits.

\begin{abstract}
Abbreviations
DGEBA: diglycidyl ether of bisphenol A; DGEBOH: diglycidyl ether of 1,4 butanediol; IPDA: isophorone diamine; SEM: scanning electron microscope; CEMUP: Centro de Materiais da Universidade do Porto; $R^{2}$ : determination coefficient.
\end{abstract}

Authors' contributions

AQB writing, experimental tests. LS writing. JA experimental tests. MF Taguchi analysis. All authors read and approved the final manuscript.

\title{
Author details
}

${ }^{1}$ INEGI, Rua Dr. Roberto Frias, 400, 4200-465 Porto, Portugal. ${ }^{2}$ Department of Mechanical Engineering, Faculty of Engineering, University of Porto, Rua Dr. Roberto Frias, $4200-465$ Porto, Portugal. ${ }^{3}$ Materials Performance Group, Materials Science and Engineering Department, Universidad Carlos III de Madrid, Leganés, Spain.

\section{Acknowledgements}

Financial support by Foundation for Science and Technology (PTDC/EME-TME/098752/2008 and SFRH/BD/88173/2012) are greatly acknowledged.

\section{Competing interests}

The authors declare that they have no competing interests.

Availability of data and materials

All relevant data of the article are presented in the manuscript (tables or figures).

Funding

Financial support by Foundation for Science and Technology (PTDC/EME-TME/098752/2008 and SFRH/BD/88173/2012).

\section{Publisher's Note}

Springer Nature remains neutral with regard to jurisdictional claims in published maps and institutional affiliations.

Received: 19 March 2017 Accepted: 19 April 2017

Published online: 24 April 2017

\section{References}

1. da Silva LFM, Öchsner A, Adams RD, editors. Handbook of adhesion technology. Heidelberg: Springer Science \& Business Media; 2011

2. Packham DE, editor. Handbook of adhesion. London: Wiley; 2005.

3. Petrie EM, editor. Handbook of adhesives and sealants. New York City: McGraw-Hill; 2000.

4. Kinloch AJ, Yuen ML, Jenkins SD. Thermoplastic-toughened epoxy polymers. J Mater Sci. 1994;29(14):3781-90.

5. Cardwell B, Yee A. Toughening of epoxies through thermoplastic crack bridging. J Mater Sci. 1998;33(22):5473-84.

6. Ramos VD, da Costa HM, Soares VLP, Nascimento RSV. Modification of epoxy resin: a comparison of different types of elastometer. Polym Test. 2005;24(3):387-94

7. Ahmad Z, Ansell MP, Smedley D. Thermal properties of epoxy-based adhesive reinforced with nano and microparticles for in-situ timber bonding international int. J Eng Technol. 2010;10(2):21-7.

8. Barbosa AQ, da Silva LFM, Banea MD, Öchsner A. Methods to increase the toughness of structural adhesives with micro particles: an overview with focus on cork particles. Materwiss Werksttech. 2016;47(4):307-25.

9. Gil L. Cork composites: a review. Materials. 2009;2(3):776-89.

10. Gil L. New cork-based materials and applications. Materials. 2009;8(2):625-37.

11. Silva SP, Sabino MA, Fernandes EM, Correlo VM, Boesel LF, Reis RL. Cork: properties, capabilities and applications. Int Mater Rev. 2005;50(6):345-65.

12. da Silva LFM, Dillard DA, Blackman B, Adams RD, editors. Testing adhesive joints: best practices. Weinheim: Wiley; 2012. 
13. Meguid SA, Sun Y. On the tensile and shear strength of nano-reinforced composite interfaces. Mater Des. 2003;25(4):289-96

14. Minfeng Z, Xudong S, Huiquan X, Genzhong J, Xuewen J, Baoyi W, Chenze Q. Investigation of free volume and the interfacial, and toughening behavior for epoxy resin/rubber composites by positron annihilation. Radiat Phys Chem. 2008;77(3):245-51.

15. Huang Y, Kinloch A. The toughness of epoxy polymers containing microvoids. Polymer. 1992;33(6):1330-2.

16. Kinloch A, Hunston D. Effect of volume fraction of dispersed rubbery phase on the toughness of rubber-toughened epoxy polymers. J Mater Sci Lett. 1987;6(2):137-9.

17. Azimi H, Pearson R, Hertzberg R. Fatique of rubber-modified epoxies: effect of particle size and volume fraction. J Mater Sci. 1996;31(14):3777-89.

18. Fu SY, Feng XQ, Lauke B, Mai BW. Effects of particle size, particle/matrix interface adhesion and particle loading on mechanical properties of particulate-polymer composites. Compos Part B Eng. 2008;39(6):933-61.

19. Nakamura Y, Yamaguchi M, Okubo M, Matsumoto T. Effects of particle size on mechanical and impact properties of epoxy resin filled with spherical silica. J Appl Polym Sci. 1992;45(7):1281-9.

20. Kitey R, Tippur H. Role of particle size and filler-matrix adhesion on dynamic fracture of glass-filled epoxy. I. Macromeasurements. Acta Mater. 2005;53(4):1153-65.

21. Nakamura Y, Yamaguchi M, Okubo M, Matsumoto T. Surface modifications of polycarbonate (PC) and acrylonitrile butadiene styrene (ABS) copolymer by treatment with atmospheric plasma. Surf Coat Technol. 2009;203(16):2173-80.

22. Barbosa AQ, da Silva LFM, Öchsner A, Abenojar J, del Real JC. Tensile strength of a brittle epoxy resin reinforced with micro cork particles: effect of size, amount and surface treatment. J Adhes. 2012;88(4-6):452-70.

23. Barbosa AQ, da Silva LFM, Öchsner A, Abenojar J. Influence of the size and amount of cork particles on the impact toughness of a structural adhesive. Microsc Microanal. 2015;21(S5):9-10.

24. Abenojar J, Barbosa AQ, Ballesteros Y, del Real JC, da Silva LFM, Martínez MA. Effect of surface treatments on natural cork: surface energy, adhesion, and acoustic insulation. Wood Sci Technol. 2014;48(1):207-24.

25. Barbosa AQ, da Silva LFM, Öchsner A, Abenojar J, del Real JC. Utilização de micro partículas de cortiça como material de reforço em adesivos estruturais frágeis. Ciência \& Tecnologia dos Materiais. 2013;25(1):42-9.

26. Banea MD, da Silva LFM, Campilho RD. Moulds design for adhesive bulk and joint specimens manufacturing. Assem Autom. 2012;32(3):284-92.

27. Taguchi G. Introduction to quality engineering: designing quality into products and processes. White Plain: Kraus International; 1986.

28. Ross PJ. Taguchi techniques for quality engineering: loss function, orthogonal experiments, parameter and tolerance design. 1988

29. Figueiredo MA, Fernandes AA. O método de Taguchi no planeamento e análise de operaçoes de soldadura. Ingenium. 1996;2(11):79-85.

30. Barbosa AQ, da Silva LFM, Abenojar J, del Real JC, Paiva RM, Öchsner A. Kinetic analysis and characterization of an epoxy/cork adhesive. Thermochim Acta. 2015;604:52-60.

31. Barbosa AQ, da Silva LFM, Öchsner A. Effect of the amount of cork particles on the strength and glass transition temperature of a structural adhesive. Proc Inst Mech Eng L J Mater Des Appl. 2013;228(4):323-33.

32. Singh $\mathrm{R}$, Zhang $\mathrm{M}$, Chan $\mathrm{D}$. Toughening of a brittle thermosetting polymer: effects of reinforcement particle size and volume fraction. J Mater Sci. 2002;37(4):781-8.

33. Lauke B. On the effect of particle size on fracture toughness of polymer composites. Compos Sci Technol. 2008;68(15):3365-72.

34. Fu SY. Effects of particle size, particle/matrix interface adhesion and particle loading on mechanical properties of particulate-polymer composites. Compos B Eng. 2008;39(6):933-61.

\section{Submit your manuscript to a SpringerOpen ${ }^{\circ}$ journal and benefit from:}

- Convenient online submission

- Rigorous peer review

- Immediate publication on acceptance

- Open access: articles freely available online

- High visibility within the field

- Retaining the copyright to your article

Submit your next manuscript at $\gg$ springeropen.com 